\title{
A Comparative Study on Human Urine and Anaerobic Septage Supernatant by Struvite Precipitation
}

\author{
Gandhimathi A. and Sneha M.
}

\begin{abstract}
Sustainable and closed-loop nutrient cycling require the recovery of valuable resources from wastewater. In comparison, source separated urine allows resource recovery from a highly concentrated nutrient stream, resulting in a more sustainable and efficient recovery practice. Different methods was studied in lab scale, but struvite precipitation was adopted. In this study the human urine sample was collected from men's restroom and the septage supernatant was pumped out from women's restroom septic tank inside the campus. Struvite precipitation was determined by crystal growth phases in- order to recover the by-product phosphate from human urine and septage supernatant. Human Urine resulted in higher efficiency than septage supernatant. Phosphorous was extracted from struvite precipitation and was used for the plant cultivation inside our campus premises.
\end{abstract}

Index Terms-Struvite, human urine, septage supernatant (SS), phosphorous.

\section{INTRODUCTION}

In the past decade, the focus of wastewater engineering has shifted from protecting human health and pollution control to sustainability and resource recovery. Resources such as ammonia and phosphate are essential for human food supply. Ammonia is mainly produced from the Haber-Bosch process, conducted under high pressure and temperature, which consumes more than $1 \%$ of the world's total energy [1]. Phosphorus is abundant in the earth's crust but its accessibility and quality are limited Morocco and China alone account for $78 \%$ of the world phosphate rock reserves [2].

Struvite (Magnesium Ammonium Phosphate) is a phosphate mineral with formula $\mathrm{NH}_{4} \mathrm{MgPO}_{4} \cdot 6 \mathrm{H}_{2} \mathrm{O}$. Struvite crystallizes in the orthorhombic system as white to yellowish or brownish-white pyramidal crystals in platey mica-like forms. It is a soft mineral with Mohs hardness of 1.5 to 2 and has a low specific gravity of 1.7. It is a sparingly soluble in neutral and alkaline condition, but readily soluble in acid. Struvite crystals are urinary tract stones. Struvite specifically is a material that is composed of magnesium, ammonium and phosphate. Struvite urinary stones and crystal form readily in the urine of humans.

Phosphorus enters the food chain after being taken up by plants, and is discharged to wastewater treatment works after excretion from the human body. Conventional centralized wastewater treatment systems, as they have been implemented in developed countries, eliminate such nutrients and can

Manuscript received January 5, 2019; revised May 5, 2019.

The authors are with Environmental Engineering, Department of Civil Engineering, Kumaraguru College of Technology, India (e-mail: gandhimathi.a.ce@kct.ac.in, snehamahal14@gmail.com). therefore be characterized as "end-of-pipe" solutions. They consume large amounts of freshwater and require an increased expenditure of funds in order to cover the costs of compliance with increasing regulatory requirements and the modification or maintenance of existing assets [3]. The alternative concept of "source control" may be an innovative way of promoting the sustainability of wastewater management, especially in developing countries where vast systems of sewer infrastructure have not yet been established. The so-called "No Mix" technology aims at collecting the various wastewater streams separately at source and treating them individually with the objective of recovering valuable nutrients and reusing the clarified water.

Human urine with little $\mathrm{Ca} 2+$ ions contains approximately $70 \%$ of the excreted nitrogen and $25 \%-60 \%$ of the excreted phosphorus [4] which would place a big burden on nitrogen and phosphorus removal in Waste Water Treatment Plants if not collected and pretreated. Therefore, human urine is regarded as an inexhaustible and easily accessible natural resource, which has been proposed as a promising feedstock for struvite crystallization [5] prior to discharge.

Struvite formation chemical formula is $\mathrm{Mg}_{2}++\mathrm{NH}_{4}+$ PO4-3 $+6 \mathrm{H}_{2} \mathrm{O} \rightarrow \mathrm{NH}_{4} \mathrm{MgPO}_{4} \cdot 6 \mathrm{H}_{2} \mathrm{O}$ (crystal form), which tells us that struvite crystals are created when magnesium, ammonia and phosphate combine in water in a mole to mole to mole ratio of 1:1:1:. Utilizing a struvite control product one is able to interrupt this $1: 1: 1$ mole to mole ratio and prevent struvite precipitation.

Struvite $\left(\mathrm{MgNH}_{4} \mathrm{PO}_{4} \cdot 6 \mathrm{H}_{2} \mathrm{O}\right)$, a proven slow-releasing fertilizer that does not burn the roots of crops, can be produced from urine. With the presence of high PO43- and $\mathrm{NH} 4+$ in the urine, and externally added magnesium $(\mathrm{Mg} 2+)$, struvite crystals can be obtained via precipitation. Studies on the thermodynamics and influencing factors of struvite precipitation from human urine have been covered in lab-scale [6], [7]. With the production of struvite, $90 \%$ PO43but merely $3 \% \mathrm{NH} 4+$ present in the urine can be recovered due to the proportionally higher ammonium than phosphate concentrations[] (Etter et al., 2011; Maurer et al., 2006), and thus subsequent steps for NH4+ removal are required. [8], [9] summarized the different $\mathrm{NH} 4+$ recovery methods from urine but these treatment processes rarely go beyond laboratory scale [10].

Although struvite is only slightly soluble in water $(1-5 \%$, much previous laboratory-based work has suggested that struvite is as effective as highly soluble mineral $\mathrm{P}$ fertiliser as a source of $\mathrm{P}$ for plants. However, the reasons for this apparent dichotomy and the particular mechanisms of struvite $P$ dissolution still remain unclear. Its low water-solubility might suggest that the release of P may be too slow for early 
crop growth, although recently found that $\mathrm{P}$ uptake rates from synthetic urine-derived struvite were fairly constant over a 30-72 day growing period. Provision of $\mathrm{P}$ uptake during early growth stages is critical for plant growth and establishment and for optimizing crop yields. To overcome soil $\mathrm{P}$ immobilisation, inorganic $\mathrm{P}$ fertilisers are often placed close to the germinating seed to encourage root growth and optimise plant $\mathrm{P}$ uptake. Numerous experiments have shown a unique yield advantage from the placement or banding of $\mathrm{P}$ fertiliser in soils with limited $\mathrm{P}$ availability due to enhancement of solution $\mathrm{P}$ content in the immediate rooting zone. This agronomic practice is increasingly viewed as an important component of more sustainable production systems on low-P soils. However, the effectiveness of placed struvite has not been evaluated in previous pot studies.

Struvite urinary stones have also been referred to as "infection stones" and "triple phosphate" stones. The term triple phosphate stems from early chemical analyses of the stones which demonstrated the presence of calcium, magnesium, ammonium, and phosphate (i.e., three cations and one anion). Carbonate ions were also commonly identified they were assumed to be associated with calcium as calcium carbonate $\left(\mathrm{CaCO}_{3}\right)$. Modern crystallographic analyses have shown that human "struvite" stones are a mixture of struvite $\left(\mathrm{MgNH}_{4} \mathrm{PO}_{4} 6 \mathrm{H}_{2} \mathrm{O}\right)$ and carbonate-apatite $\left(\mathrm{Ca} 10[\mathrm{P0} 4] 45 \mathrm{CO}_{3}\right)$. Calcite $\left(\mathrm{CaCO}_{3}\right)$ is extremely rare (we have found one calcite stone in 20,000 stone analyses) and may be an artifact. In some stones, struvite may be more abundant, whereas in other stones apatite may predominate. There is good evidence to link the formation of struvite and carbonate-apatite stones to urinary infection.

Similarly, literature studies on pilot or full-scale demonstrations for struvite recovery from urine are very sparse. [11] implemented struvite reactors to study the feasibility of recovering struvite from a small village in Nepal aimed for low-cost installation and operations. The pilot study by [12] studied the efficiency of phosphorus and nitrogen removal/recovery from human urine by struvite precipitation.

Urine-collecting systems and their affinity for blockages, caused by the precipitation of inorganic compounds in pipes and storage tanks, were studied thoroughly by [13]. Whereas a lot of research has been performed in understanding the precipitation thermodynamics of struvite and the major influencing parameters (e.g., magnesium dosage, mixing rate, and $\mathrm{pH}$ ) at laboratory scale[14].The scope of this work is to examine the composition of stale/fresh human urine and septage supernatant and to identify the simultaneous efficiencies of phosphorus from the septage supernatant and human urine under various factors like $\mathrm{pH}$ and reacting time by struvite crystallization process. Comparing the efficiencies of by products like phosphorous from urine and anaerobic sludge supernatant. our work focuses rather on the implementation of urine and septage supernatant treatment technologies at pilot scale and explores the practical aspects of nutrient recovery.

\section{MATERIALS AND METHODS}

\section{A. Urine and Sludge Supernatant Source}

The fresh urine samples were collected from men's dormitory. A No Mix sanitation system was installed in a dormitory at the Kumaraguru college of technology. The dormitory accommodated 100 male students in ten rooms with bathroom. Each of the ten bathrooms was equipped with one waterless urinal and one No Mix toilet, which operates with only small amounts of flushing water for urine. The urine was discharged via two separate pipe networks (urinals, toilets) into one common storage tank located behind the dormitory. Diluted urine (mixture of urine from waterless urinals and No Mix toilets which use small amounts of flushing water, dilution factor of around 3) originated from this storage tank at the test site. Undiluted urine was collected from 100 male students living in a neighboring dormitory, who directly urinated into plastic bottles. Undiluted urine was stored in a large plastic tank. In both cases, the urine was completely hydrolyzed and had a $\mathrm{pH}$ value of 9.1 and 9.6 for undiluted and diluted urine, respectively.

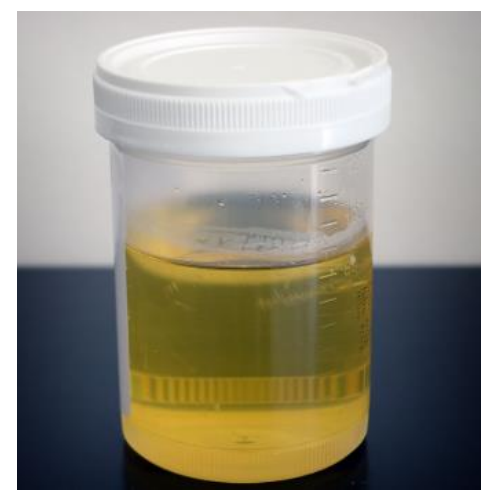

Fig. 1. Urine sample.

The urine was pumped into the precipitation reactor by using a submersible pump. Sodium hydroxide $(\mathrm{NaOH}, 50 \%)$ and sulfuric acid solutions (H2SO4, 1:10 vol.) were prepared by using $\mathrm{NaOH}$ pellets and $\mathrm{H} 2 \mathrm{SO} 4$ (96-98\%). The solution $\mathrm{pH}$ would increase caused by the urine hydrolysis, so it was used as the indicator for the completion of hydrolysis reaction. The stale urine samples were completely hydrolyzing after 7 days. The urine sample was placed in $500 \mathrm{~mL}$ sealed beakers and the supernatant was collected to measure NH4+-N concentration after $3000 \mathrm{rpm}$ stirring for $10 \mathrm{~min}$. The concentrations of magnesium and calcium ions in the stale urine samples were very low since they had already been precipitated as $\mathrm{Mg}_{3}(\mathrm{PO} 4)_{2}$ or $\mathrm{Ca}_{3}(\mathrm{PO} 4)_{2}$ spontaneously. The anaerobic sludge supernatant was collected from men's restroom septic tank at $\mathrm{KCT}$ campus.

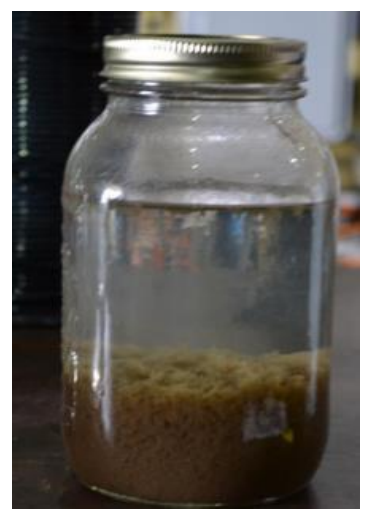

Fig. 2. Septage supernatant. 


\section{B. Sample Collection and Analysis}

Samples were collected after each of the sedimentation process in order to determine the efficiency of the phosphate recovery at different sedimentation hours. A composite sample of the precipitates generated from urine sample was analyzed at SITRA (South Indian Textile Research Association) for its crystal structure by X-ray diffraction spectroscopy (XRD). Data is generally expressed as the observed mean, followed by its standard error $( \pm \mathrm{SE})$. The concentrations of PO43--P and TP were measured using spectrophotometer according to the molybdenum blue method in Standard Methods. The analysis of NH4+-N concentration was also conducted in accordance with Standard Methods and the determination of urea concentration was also performed by p-dimethyl amino benzaldehyde colorimetric method. The suspension $\mathrm{pH}$ was measured using $\mathrm{pH}$ meter.

\section{Struvite Precipitation}

The struvite reactor was equipped with a stirrer and opening for the dosage of magnesium and sodium hydroxide addition. In the precipitation reactor, $\mathrm{MgO}$ was dosed with a $\mathrm{Mg} / \mathrm{P}$ molar ratio of 1.5:1 to a volume of $5 \mathrm{~L}$ of stored urine in order to initiate struvite precipitation. The mixture was stirred for $30 \mathrm{~min}$, followed by a $3 \mathrm{~h}$ sedimentation phase during which the struvite particles were left to settle down. The phosphorus-depleted supernatant was then transferred to a separate holding tank, whereas the precipitate was collected in a filter bag made of synthetic fabric. The filter bag was dried for $48 \mathrm{~h}$ at $105^{\circ} \mathrm{C}$ and the generated amount of struvite was determined by weighing. Precipitation experiments with a $3 \mathrm{~h}$ sedimentation phase was performed with urine (nine replications). Similar procedure was carried out for septage supernatant.

\section{RESULTS AND DISCUSSION}

The chemical composition of the human urine and septage supernatant was studied. Initially the samples were collected and the tests were carried out in the struvite reactor. In order to maintain the $\mathrm{pH}$ in the basic condition $\mathrm{NaOH}$ was added. For various sedimentation duration the $\mathrm{PO}_{4}-\mathrm{P}$ input and output was recorded and its efficiency was studied.

The precipitation of struvite is a highly efficient treatment method for recovering phosphorus from human urine. For both diluted and undiluted urine, PO4-P-removal rates of $97 \%$ could be achieved in the precipitation reactor. The cost-efficiency of the treatment process was highest when running the plant with undiluted urine. In this case, larger quantities of precipitate were generated with each treatment cycle and the amount of material remaining trapped in the filter fabric was negligible.

During the stage of precipitation, the concentrations of soluble orthophosphates in urine decreased on average from $311 \pm 9 \mathrm{mg} \mathrm{PO}_{4}-\mathrm{P} \mathrm{L}-1$ to $5 \pm 0.4 \mathrm{mg} \mathrm{PO}_{4}-\mathrm{P} \mathrm{L}-1$. This corresponds to a PO4-P-removal efficiency of $98 \%$. With an average starting load of $16 \pm 0.4 \mathrm{~g}$ PO4-P contained in $50 \mathrm{~L}$ of undiluted urine, $112 \pm 10 \mathrm{~g}$ of struvite could be generated. For diluted urine, phosphate concentrations decreased from $111 \pm 1 \mathrm{mg} \mathrm{PO}_{4}-\mathrm{P} \mathrm{L}-1$ to $2 \pm 0.2 \mathrm{mg} \mathrm{PO}_{4}-\mathrm{P} \mathrm{L}-1$; thus, again achieving a $\mathrm{PO}_{4}-\mathrm{P}$-removal efficiency of $98 \%$. From diluted urine, only $32 \pm 2 \mathrm{~g}$ of struvite could be generated from a starting load of $6 \pm 0.1 \mathrm{~g} \mathrm{PO}_{4}$-P. Decreasing the sedimentation time from 3 to $1 \mathrm{~h}$ did not have a significant impact on phosphate removal efficiencies, as shown in Table 1.

TABLE I: PHOSPHATE REMOVAL EFFICIENCY (\%) FROM URINE BY STRUVITE PRECIPITATION IN THE PRECIPITATION REACTOR AFTER 1, 2 AND 3 HRS OF

\begin{tabular}{|l|l|l|l|l|}
\hline S. No & $\begin{array}{l}\text { Sedimentation time } \\
(\mathrm{hrs})\end{array}$ & 1 (hrs) & $2(\mathrm{hrs})$ & $3(\mathrm{hrs})$ \\
\hline 1. & $\begin{array}{l}\mathrm{PO}_{4}-\mathrm{P} \text { urine input } \\
(\mathrm{mg} / \mathrm{L})\end{array}$ & $103 \pm 1.0$ & $109 \pm 0.3$ & $112 \pm 4.0$ \\
\hline 2. & $\begin{array}{l}\mathrm{PO}_{4}-\mathrm{P} \text { urine output } \\
(\mathrm{mg} / \mathrm{L})\end{array}$ & $3 \pm 0.0$ & $3 \pm 0.3$ & $2 \pm 0.3$ \\
\hline 3. & $\begin{array}{l}\text { PO }-\mathrm{P} \text { removal } \\
\text { efficiency (\%) }\end{array}$ & $97 \pm 0.3$ & $98 \pm 0.2$ & $98 \pm 0.2$ \\
\hline
\end{tabular}

Decreasing the sedimentation time was from 180 minutes to 60 minutes did not have a significant impact on phosphate removal efficiencies as shown in Table I. These findings were confirmed by bench-scale experiments in which the precipitation reactor was replaced by a jar tester (stirring) and Imhoff cones (sedimentation) as shown in Table $2 \& 3$ and the corresponding graphs in the Fig $1 \& 2$.

$\mathrm{X}$-ray diffraction spectroscopy results have shown that $15 \%$ of the sample dried at $105^{\circ} \mathrm{C}$ was composed of dittmarite, which is a dehydration product of struvite. [15] and [16] found that crystalline struvite is thermally stable up to a temperature of $55^{\circ} \mathrm{C}$. From this temperature, and depending on the rate of heating, it can give off $\mathrm{NH} 3$ and $\mathrm{H} 2 \mathrm{O}$ molecules. The weight loss is complete when the temperature reaches $250^{\circ} \mathrm{C}$. Similarly, dittmarite can rehydrate to struvite at room temperature by absorbing water molecules. [17] suggest that, in terms of solubility in ammonium citrate solution, the phosphate availability of struvite is higher than that of dittmarite. In order to prevent the loss of water molecules from the crystal structure, the recovered struvite particles should be air-dried or dried at a temperature lower than $55^{\circ} \mathrm{C}$. On the other hand, the monohydrate has a higher phosphorus content than struvite ( $19.9 \%$ vs. $12.6 \%$, respectively) and could therefore be more profitable from the fertilizer transportation point of view. In any case, either product can easily be generated by simply using different temperature settings when drying the urine-derived particles: $<55^{\circ} \mathrm{C}$ for obtaining struvite and $>250^{\circ} \mathrm{C}$ for dittmarite.

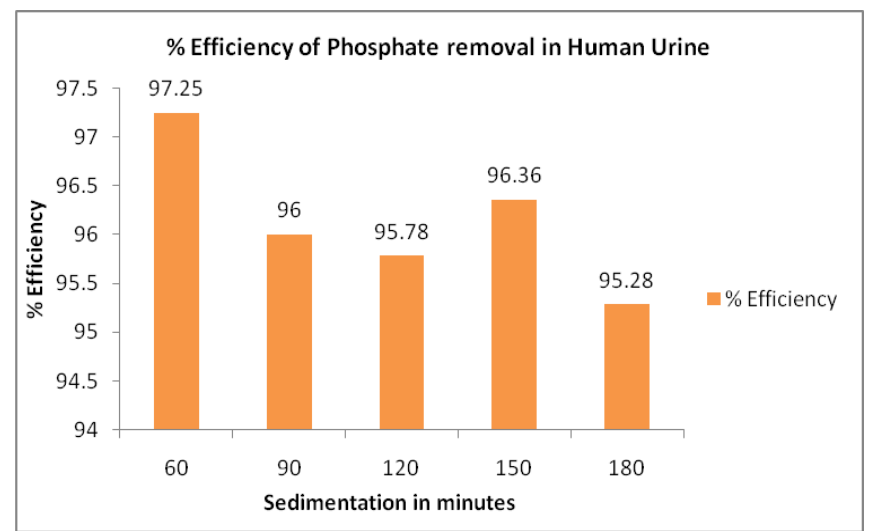

Fig. 3. Graph representing efficiency of $\mathrm{PO}_{4}-\mathrm{P}$ in human urine (settleability). 
TABLE II: REPRESENTING THE PO $_{4}$-P IN SEPTAGE SUPERNATANT

\begin{tabular}{|l|l|l|l|l|l|}
\hline $\begin{array}{l}\text { Sedimentati } \\
\text { on time(hrs) }\end{array}$ & $\begin{array}{c}60 \\
\min \end{array}$ & $\begin{array}{c}90 \\
\min \end{array}$ & $\begin{array}{l}120 \\
\min \end{array}$ & $\begin{array}{l}150 \\
\text { min }\end{array}$ & $180 \mathrm{~min}$ \\
\hline $\begin{array}{l}\mathrm{PO}_{4}-\mathrm{P} \text { urine } \\
\text { input (mg/L) }\end{array}$ & $\begin{array}{l}85 \pm 0 . \\
1\end{array}$ & $102 \pm 0.3$ & $\begin{array}{l}90 \pm 0 . \\
4\end{array}$ & $82 \pm 0.2$ & $96 \pm 0.1$ \\
\hline $\begin{array}{l}\mathrm{PO} \text {-P urine } \\
\text { output } \\
\text { (mg/L) }\end{array}$ & $20 \pm 0$. & $29 \pm 0.3$ & $\begin{array}{l}22 \pm 0 . \\
3\end{array}$ & $18 \pm 0.1$ & $25 \pm 0.2$ \\
\hline $\begin{array}{l}\text { PO-P } \\
\text { removal } \\
\text { efficiency } \\
(\%)\end{array}$ & 76.47 & 71.56 & 75.56 & 78.04 & 73.95 \\
\hline
\end{tabular}

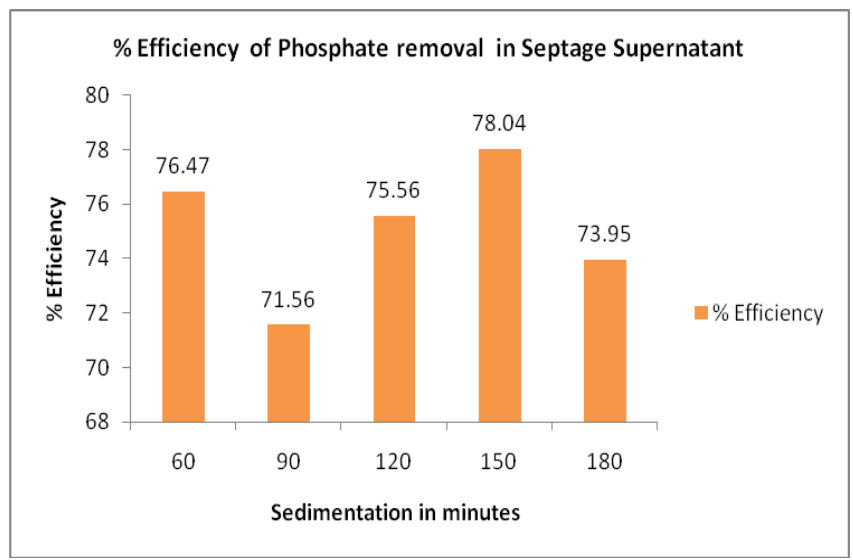

Fig. 4. Graph representing efficiency of $\mathrm{PO}_{4}-\mathrm{P}$ septage.

TABLE III: REPRESENTING THE $\mathrm{PO}_{4}$-P in HUMAN URINe

\begin{tabular}{|l|l|l|l|l|l|}
\hline $\begin{array}{l}\text { Sedimentat } \\
\text { ion } \\
\text { time(hrs. }\end{array}$ & $60 \mathrm{~min}$ & $90 \mathrm{~min}$ & $120 \mathrm{~min}$ & $150 \mathrm{~min}$ & $\begin{array}{l}180 \\
\mathrm{~min}\end{array}$ \\
\hline $\begin{array}{l}\mathrm{PO}_{4}-\mathrm{P} \\
\text { urine input } \\
(\mathrm{mg} / \mathrm{L})\end{array}$ & $109 \pm 0$ & $125 \pm 0.3$ & $95 \pm 0.4$ & $110 \pm 0.2$ & $\begin{array}{l}106 \pm 0 . \\
1\end{array}$ \\
\hline $\begin{array}{l}\mathrm{PO}_{4}-\mathrm{P} \\
\text { urine } \\
\text { output } \\
\text { (mg/L) }\end{array}$ & $3 \pm 0.2$ & $5 \pm 0.3$ & $4 \pm 0.3$ & $4 \pm 0.1$ & $5 \pm 0.2$ \\
\hline $\begin{array}{l}\mathrm{PO}_{4}-\mathrm{P} \\
\text { removal } \\
\text { efficiency } \\
(\%)\end{array}$ & 97.25 & 96 & 95.78 & 96.36 & 95.28 \\
\hline
\end{tabular}

\section{CONCLUSION}

The results suggest that struvite precipitation is a highly efficient method for removing phosphorus. Phosphorus recovery was most efficient with urine because larger amounts of particles were generated with each treatment cycle, and the amount of material remaining trapped in the filter material was negligible. The efficiency of the human urine was comparatively higher in comparison with the septage supernatant since the composition of the human urine is much efficient in the phosphate removal but not the septage supernatant. Since the septage supernatant consisted of water, urine and human feces. The phosphate that is obtained by the struvite precipitation is used for the plant cultivation that is premesis. But the separation of urine from the septage is a tedious process. A "No Mix" sanitation system was installed in a dormitory at the KCT, with the objective of recycling nutrients from source separated wastewater. The "Yellow
Water" treatment plant was assessed for its efficiency in recovering phosphorus from human urine. The pilot plant achieved phosphorus removal efficiencies of $98 \%$ with human urine in comparison with the septage supernatant. Phosphorus was recovered in the form of struvite, a solid mineral fertilizer.

\section{MERITS AND DEMERITS}

Merits

- Volume and weight of carrying urine is reduced.

- Nutrients can be stored over time.

- Handling is more user-friendly in powder form.

- Bio-available: The nutrients in struvite can be readily absorbed by the plant.

- Slow-release: Due to its low solubility, struvite guarantees a slow but steady nutrient supply.

- Highly pure: contaminants (e.g. pharmaceuticals or heavy metals), which may be present in the urine, do not precipitate with the struvite.

- No bad smell

- Simple technology: It could be built wherever it is required.

- Construction with local materials.

- Easy operation (no electricity).

Demerits

- High cost for the set-up of the reactor and the urine collection system.

- Dependent on the socio-cultural acceptability.

- Limited knowledge on the part of the farmers.

- High volumes of urine required.

- Low yields (approximately $1 \mathrm{~kg}$ struvite from $500 \mathrm{~L}$ urine).

- Partial recovery of nitrogen and no recovery of potassium.

- Requires soluble magnesium source.

- Transport costs of urine (to the struvite production site) reduce economic viability.

- Effluent requires treatment or controlled reuse (i.e. fertigation).

- Possible corrosion of metal appliances.

\section{ApPlicAtion in AGRICUlture}

Struvite precipitation may be appropriate for any situation where significant quantities of urine can be collected. Struvite an be produced from a variety of wastewaters (including domestic wastewater or liquid animal manure) but the process is more difficult and requires additional chemicals for $\mathrm{pH}$ control. Urine collection (labour) and transport (fuel) accounts for a large proportion of the costs, and therefore struvite production is more appropriate for areas where large volumes of urine are available within a small area public toilets, schools and stadia are promising sources of urine.

According to its chemical composition, struvite has an NPK-value of approximately 6:29:0: (Mg) 10 . It shows some advantageous properties like a slow nutrient release and good $\mathrm{P}$ availability. As regards the plant availability of phosphorus 
(P) from struvite, it was found that there is no significant difference between struvite and mono-calcium phosphate, a source of water soluble $\mathrm{P}$ that is generally considered to be fully plant available. However, the plant available nitrogen is not enough for optimal growth, but higher struvite application would significantly increase the soil $\mathrm{pH}$ level to a degree where it might have negatively affected nutrient availability and uptake. Moreover, the magnesium content is very high. In general, the average amount of nutrients that should be applied to the soil should follow the order $\mathrm{N}>=\mathrm{K}>\mathrm{P}>\mathrm{Mg}$. It is therefore suggested that for an optimal use, a combination of other fertilizers together with struvite should be used. Especially an increase of the nitrogen content would be advisable since nitrogen is the nutrient that most of the farmers look for. Most suitably a ready-made mixture with an optimal nutrient ratio could be supplied.

One of the big advantages of Struvite that might be recognized by the local farmers is for its purity and product reliability. Whereas the industrially supplied chemical fertilizers are likely to be polluted with unwanted side products and heavy metals, even when coming from official channels. For fertilisers coming from informal sources $(>60 \%)$ even the actual nutrient concentration itself is of big question. As locally produced fertilizer like struvite would surely get more credit from farmers because its source is known and a reliable availability can be expected. This might even be a factor supporting a higher price compared to other fertilizers.

Struvite had greatly enhanced solubility in the presence of organic acid anions buckwheat, which exudes a high level of organic acids, was more effective at mobilising struvite $\mathrm{P}$ than the low level exuder, spring wheat. Struvite granules placed with the seed did not provide the same rate of $\mathrm{P}$ supply as placed Diammonium phosphate granules for early growth of spring wheat, but gave equivalent rates of $\mathrm{P}$ uptake, yield and apparent fertiliser recovery at harvest, even though only $26 \%$ of struvite granules completely dissolved. Fertiliser mixes containing struvite and Diammonium phosphate applied to spring wheat have potential to provide both optimal early and late season $\mathrm{P}$ uptake and improve overall $\mathrm{P}$ use efficiency.

\section{SCOPE OF WORK}

Since the separation of urine is a tedious process and separate collection unit is required for the urine separation. The scope of the study is to combine the struvite precipitation in the mixed proportion of the human urine and the septage supernatant in the next study.

\section{CONFLICT OF INTEREST}

The authors declare no conflict of interest.

\section{AUTHOR CONTRIBUTIONS}

A. Gandhimathi and Sneha M. conducted the experiment. Sneha M. analysed and wrote the entire paper.

\section{REFERENCES}

[1] N. Cherkasov, A. O. Ibhadon, and P. Fitzpatrick, "A review of the existing and alternative methods for greener nitrogen fixation," Chem. Eng. Process., vol. 90, pp. 24-33, 2015.

[2] M. S. Jasinski, "Phosphate rock," U.S. Geological Survey, 2017.

[3] T. A. Larsen et al., "Re-engineering the toilet for sustainable wastewater management," Environ Sci Technol., 2001, vol. 35, pp. 192A-7A.

[4] E. J. D. Helstrom and K. Grennberg, "Storage of human urine acidification as a method to inhibit decomposition of urea," Ecological Engineering, 1999, vol. 17.

[5] M. S. Rahaman, D. S. Mavinic, and N. Ellis, "Effects of various process parameters on struvite precipitation kinetics and subsequent determination of rate constants," Water Science \& Technology, 2008, p. 647.

[6] M. Ronteltap, M. Maurer, and W. Gujer, "Struvite precipitation thermodynamics in sourceseparated urine," Water Res., vol. 41, no. 5, pp. 977-984, 2007.

[7] M. Ronteltap et al., "Struvite precipitation from urine Influencing factors on particle size," Water Res., vol. 44, no. 6, pp. 2038-2046, 2010.

[8] B. Etter et al., "Low-cost struvite production using source separated urine in Nepal," Water Res., vol. 45, no. 2, pp. 852-862, 2011.

[9] M. Maurer et al., "Treatment processes for source-separated urine," Water Res., vol. 40, no. 17, pp. 3151-3166, 2006.

[10] Y. V. Nancharaiah et al., "Recent advances in nutrient removal and recovery in biological and bioelectrochemical systems," Bioresour. Technol., vol. 215, pp. 173-541, 185, 2016.

[11] B. Etter et al., "Low-cost struvite production using source-482 separated urine in Nepal," Water Res., vol. 45, no. 2, pp. 852-862, 2011.

[12] S. Antonini et al., "Nitrogen and phosphorus recovery from human urine by struvite precipitation and air stripping in Vietnam," Clean-Soil Air Water, vol. 39, no. 12, pp. 1099-1104, 2011.

[13] K. M. Udert, T. A. Larsen, M. Biebow, and W. Gujer, "Urea hydrolysis and precipitation dynamics in a urine-collecting system," Water Research, 2003, pp. 2571-2582.

[14] J. A. Wilsenach et al., "Phosphate and potassium recovery from source separated urine through struvite precipitation," Water Res., vol. 41, no. 2, pp. 458-466, 2007.

[15] A. K. Sarkar, "Hydration dehydration characteristics of struvite and dittmarite pertaining to magnesium ammonium phosphate cement systems," J Mater Sci., vol. 26, pp. 2514-8, 1991.

[16] M. I. H. Bhuiyan et al., "Thermal decomposition of struvite and its phase transition," Chemosphere, 2008, vol. 70, pp. 1347-56.

[17] G. L. Bridger et al., "Micronutrient sources - metal ammonium phosphates as fertilizers," J Agric Food Chem., 1962, vol. 10, pp. 181-8.

Copyright (C) 2019 by the authors. This is an open access article distributed under the Creative Commons Attribution License which permits unrestricted use, distribution, and reproduction in any medium, provided the original work is properly cited (CC BY 4.0).

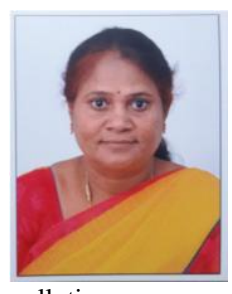

pollution.

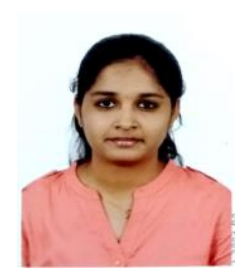

A. Gandhimathi got the B.E-civil engineering at Government College of Technology, Coimbatore (1991), the M.E-environmental engineering at Government College of Technology, Coimbatore (2007), the Ph.D.-soil pollution at Anna University, Chennai. She was an assistant professor, Karpagam College of Technology, Coimbatore from 2001-2009, etc. Her research interests are soil pollution and air

Sneha M. got the B.E civil engineering, Kumaraguru College of Technology, Coimbatore in 2018. She is now pursuing the M.E environmental engineering, CoiOmbatore. 